\title{
Cognitive Gains of Aerobic Exercise in Patients With Ischemic Cerebrovascular Disorder: A Systematic Review and Meta-Analysis
}

\section{OPEN ACCESS}

Edited by:

Trygve Tollefsbol,

University of Alabama at Birmingham,

United States

Reviewed by:

Wucheng Tao,

Fujian Medical University, China

Natsuki Hasegawa,

Ritsumeikan University, Japan

*Correspondence:

Ting Wu

wuting80000@126.com

tThese authors have contributed equally to this work

Specialty section:

This article was submitted to Epigenomics and Epigenetics,

a section of the journal

Frontiers in Cell and Developmental

Biology

Received: 11 July 2020 Accepted: 03 December 2020 Published: 18 December 2020

Citation:

Shu Y, He Q, Xie Y, Zhang W, Zhai S and Wu T (2020) Cognitive Gains of

Aerobic Exercise in Patients With Ischemic Cerebrovascular Disorder: A Systematic Review and Meta-Analysis.

Front. Cell Dev. Biol. 8:582380

doi: $10.3389 /$ fcell.2020.582380

\author{
Yimei Shu ${ }^{1+}$, Qing $\mathrm{He}^{2 \dagger}$, Yi Xie ${ }^{1}$, Wanrong Zhang ${ }^{1}$, Shuang Zhai ${ }^{1}$ and Ting $\mathrm{Wu}^{1 *}$ \\ ${ }^{1}$ Department of Neurology, The First Affiliated Hospital of Nanjing Medical University, Nanjing, China, ${ }^{2}$ Department of \\ Neurology, Xuzhou First People's Hospital, The Affiliated Xuzhou Municipal Hospital of Xuzhou Medical University, Xuzhou, \\ China
}

Background: Cognitive impairment has become an important problem in ischemic cerebrovascular disorder survivors as disease related deaths have been significantly reduced. Aerobic exercise, the most prevalent mode of physical activity, positively contributes to cognition in both healthy population and people with cognitive impairment. However, studies on its associations with cognitive gains in patients with ischemic cerebrovascular disease showed mixed findings.

Objective: To explore the cognitive effects of aerobic exercise on ischemic cerebrovascular disorder survivors and investigate the possible moderators on exercise benefits.

Method: Randomized controlled trials investigating the effects of sole aerobic exercise on cognitive function in population with ischemic intracranial vascular disorder compared to any control group who did not receive the intervention were enrolled in this systematic review and meta-analysis. Four online database (Pubmed, Cochrane Library, Embase, and Web of Science) were searched.

Results: The initial search returned 1,522 citations and ultimately 11 studies were included in the systematic review. Analysis of seven studies showed the beneficial but not statistically significant impact of aerobic exercise on global cognitive function $(0.13 ; 95 \%$ $\mathrm{Cl}-0.09$ to $0.35 ; p=0.25)$. Participants already with cognitive impairment benefited more from this intervention $(0.31 ; 95 \% \mathrm{Cl} 0.07-0.55 ; p=0.01)$ and moderate intensity might be the optimal choice $(0.34 ; 95 \% \mathrm{Cl}-0.01$ to $0.69 ; p=0.06)$. The program duration and initiation time after stroke occurrence did not predict better cognitive outcome. Aerobic exercise was not associated with improvement of processing speed and executive function, the two subdomains of cognitive function.

Conclusions: Aerobic exercise may contribute to cognitive gains in survivors of ischemic cerebrovascular disorder, especially for population already with cognitive decline. Our findings suggest that the adoption of moderate intensity aerobic exercise might improve cognition in such population.

Keywords: stroke, cognition, aerobic exercise, systematic review, meta-analysis, ischemic cerebrovascular disease 


\section{INTRODUCTION}

Cerebrovascular disorder is one of the most prevalent diseases in old adults. With the reduction of fatal risk, the incidence of cognitive impairment or dementia in survivors of such kind of disease has also increased, exerting heavy burden on family and the society (Hurd et al., 2013). Vascular dementia, the most severe stage of cognitive impairment derived from vascular factors, is the most common cause of dementia second only to Alzheimer's disease (Gorelick et al., 2011). Stroke is the most important and prevalent disease type of ischemic cerebrovascular disorder and approximately $30 \%$ of the survivors are estimated to develop dementia. The risk is three to five times greater than those without any stroke history (Kalaria et al., 2016). Recent evidence also suggests the central role of small blood vessel disease in vascular dementia development (Dichgans and Leys, 2017; Wallin et al., 2018). The development of cognitive impairment from the occurrence of ischemic cerebral vascular disease is complex as vascular, neurodegenerative or mixed processes are involved (Kalaria et al., 2016). The variations such as disease type, location, number of lesions, and severity all make the symptoms complicated. The location, in particular, is closely associated with specific cognitive domains. For instance, the prefrontal and parietal circuits is associated with executive function (Colcombe and Kramer, 2003) while the frontal lobe is in charge of working memory and processing speed (Stephens et al., 2004). At present, the main strategy to manage cognitive decline after ischemic cerebrovascular disorder is prevention. However, evidence is still controversial among the preventive strategies (Van der Flier et al., 2018).

Apart from improving physical fitness, increasing evidence suggests the strong link between aerobic exercise and brain cognitive health. Aerobic exercise is beneficial to alleviate hypertension, atherosclerosis, diabetes mellitus, high cholesterol, which are all potential contributors to cerebrovascular disease and vascular cognitive deterioration (Sahathevan et al., 2012). One of the molecular mechanisms is the protection effect on endothelium against oxidative stress and inflammation (Palmefors et al., 2014; Luca and Luca, 2019). As the consumption of oxygen and energy is high in brain, chronic cerebral hypoperfusion is a crucial promotor of cognitive dysfunction (Duncombe et al., 2017) and aerobic exercise can attenuate this reduction (Moraine et al., 1993). However, whether the vascular benefits of aerobic training can predict cognitive gains still needs further exploration. Neurogenesis is one of the processes associated with improved cognition (Van Praag et al., 1999). Aerobic training is also positively associated with synaptic plasticity, the essential biological change for memory, and learning. It is involved in both long-term potentiation enhancement and long-term depression induction (Bettio et al., 2019). Neuron density and gray matter volumes are increased in hippocampus, prefrontal and cingulate cortices after physical activity (Ruscheweyh et al., 2011; Kleemeyer et al., 2016). Moreover, Aerobic exercise is found to positively impact several important neurotransmitters and neurotrophic factors, including dopamine (Loprinzi et al., 2013), brain-derived neurotrophic factor (BDNF) (Vaynman et al., 2004), vascular endothelial growth factor (VEGF) (Ding et al., 2006b) and insulin-like growth factor-1 (IGF-1) (Ding et al., 2006a).

Several exercise modes have been practiced in hope of improving cognitive functions in ischemic cerebrovascular disorder survivors (Schmidt et al., 2013; Tiozzo et al., 2015; Han et al., 2017). Here, we conduct a meta-analysis review on the cognitive effects of aerobic exercise in patients with ischemic cerebrovascular disorder. We also explore the modulation of population and exercise characteristics on the training efficacy. This analysis can be provided important implication for ways to maximize cognitive benefits.

\section{METHODS}

We conducted the systematic review and meta-analysis complying with established guidelines from Preferred Reporting Items for Systematic Reviews and Meta-Analysis (PRISMA).

\section{SEARCH STRATEGY}

We searched the electronic database Pubmed, Cochrane Library, Embase and Web of Science for clinical trials published in English up to October 2020. The search strategy was composed of the following items: (cerebrovascular disorder) OR (cerebral OR brain OR cranial OR intracranial) AND (vascular OR vessel OR hemorrhage OR infarction OR stroke) AND (cognition OR cogniti* OR neuropsychological OR attention OR memory OR processing OR language OR visuospatial OR executive function OR dementia) AND (aerobic OR endurance OR exercise). Terms were searched in "All Fields" and medical subject headings (MeSH) was also used for "cerebrovascular disorder," "cognition" and "stroke." Reference lists had also been examined to look up for other possibly relevant articles.

\section{STUDY SELECTION}

Studies were included if they met all of the following criteria: (1) Participants with ischemic cerebrovascular disorder which were confirmed by clinical evidence. Studies focusing on participants with rick factors for intracranial ischemia like diabetes or high blood pressure but without structured vascular impairment in brain were excluded. There was no limitation on the baseline cognitive status. However, studies including samples with other neurological or mental disease were ruled out. (2) Monitored and structured aerobic exercise, regardless of intensity, duration or frequency. The training program should last for at least 4 weeks. Studies combining aerobic exercise with other physical intervention (for example, stretching exercise) were also included if aerobic exercise was the only difference in intervention between groups. (3) A supervised control group with usual care, educational program or other physical training mode except aerobic exercise. Educational program should not specifically provide information about physical activity. (4) At least one valid neuropsychological test of cognitive function with data available before and in the end of intervention. (5) Randomized controlled trials. 


\section{DATA COLLECTION AND EXTRACTION}

Dr. Shu performed the initial search, removed the duplicates and cleared out the apparent non-related articles according to title and abstract. The abstract of the remaining studies were assessed independently by Dr. He and Dr. Xie and full text was obtained for possibly eligible studies. Then, Dr Shu and Dr He reviewed the full text of each article independently in accordance with the inclusion and exclusion criteria. Conflicts were discussed between the researchers and consensus was reached. Information on participants, strategy for intervention and control groups, cognitive outcome were extracted by one researcher using a standardized form. We extracted mean, standard deviation and number of participants of each assessment from all eligible studies. We used final measurement values for analysis as most studies did not provide the change from baseline. Missing final measurement value was calculated if baseline measurement values and the changes were provided, using the formula: $\mathrm{SD}_{\text {final }}=\frac{2 \times \mathrm{R} \times \mathrm{SD}_{\text {base }}+\sqrt{4 \times \mathrm{R}^{2} \times \mathrm{SD}_{\text {base }}^{2}-4 \times \mathrm{SD}_{\text {base }}^{2}+4 \times \mathrm{SD}_{\text {change }}^{2}}}{2}$, $R=0.5$. The value for $R$ was based on the assumption that there was a moderate correlation between measures before and after intervention. This method was proved feasible in previous publications (Gates et al., 2013). When mean and SD were unavailable with sample size $(\mathrm{N})$, median $(\mathrm{Q} 2)$, first quartile (Q1) and third quartile (Q3) provided, we calculated mean and SD using the formula respectively: mean $=(\mathrm{Q} 1+\mathrm{Q} 2+\mathrm{Q} 3) \quad 3, \mathrm{SD}=\frac{\mathrm{Q} 3-\mathrm{Q} 1}{2 \times \operatorname{norminv}\left(\frac{0.75 \times \mathrm{Q} 3-0.125}{\mathrm{Q} 3+0.25}, 0,1\right)} \quad$ (Wan et al., 2014; Luo et al., 2018). And in three studies (Bo et al., 2019; Ploughman et al., 2019; Rosenfeldt et al., 2019), subgroup data was provided separately and we obtained the total mean and SD using the formula: mean $=\frac{N_{1} \times M_{1}+N_{2} \times M_{2}}{N_{1}+N_{2}}$, $\mathrm{SD}=\sqrt{\frac{\left(\mathrm{N}_{1}-1\right) \times \mathrm{SD}_{1}^{2}+\left(\mathrm{N}_{2}-1\right) \times \mathrm{SD}_{2}^{2}+\frac{\mathrm{N}_{1} \times \mathrm{N}_{2}}{\mathrm{~N}_{1}+\mathrm{N}_{2}} \times\left(\mathrm{M}_{1}^{2}+\mathrm{M}_{2}^{2}-2 \times \mathrm{M}_{1} \times \mathrm{M}_{2}\right)}{\mathrm{N}_{1}+\mathrm{N}_{2}-1}}, \mathrm{M}$ standing for mean value.

\section{QUALITY ASSESSMENT}

The methodological quality was assessed by Dr Xie and Dr Zhang separately in accordance with Cochrane risk-of-bias tool. Seven sections, namely, random sequence generation, allocation concealment, blinding of participants and personnel, blinding of outcome assessment, incomplete outcome data, selective reporting, and other bias were evaluated in each included study and were rated low, unclear (missing or deficient information) or high risk of bias depending on data provided. Disagreement was discussed and consensus was reached.

\section{DATA SYNTHESIS AND ANALYSIS}

The meta-analysis was carried out using RevMan 5.3 (Review Manager (RevMan) [Computer program]. Version 5.3. Copenhagen: The Nordic Cochrane Center, The Cochrane Collaboration, 2014). We calculated standardized mean difference (SMD) together with $95 \% \mathrm{Cl}$, as variant scales were utilized to measure cognitive status. For outcome with larger index indicating worse cognitive condition, it was entered into the software as a negative number. We used $\mathrm{Chi}^{2}$ test to assess heterogeneity between trial results. Considering its low power under the circumstance of small sample size or small number of studies included, a $p$ value $<0.1$ was regarded statistically important between-trial heterogeneity. We also used a random-effects model as the fixed model would offer narrower $\mathrm{Cls}$ although the same quantitative conclusions.

We first assessed whether aerobic exercise exerted significant and positive effect on global cognition. Subgroup analysis was conducted to explore whether characteristics of participants, intervention and measurement moderated the influence. For population characteristic, we mainly focused on baseline cognitive status (cognitive impairment or normal cognitive status). Cognitive impairment was defined as Addenbrooke's Cognitive Examination-Revised (ACER) Score $<82$ or Montreal Cognitive Assessment (MoCA) Score $<26$. Characteristics of intervention included intensity (light or moderate or vigorous, Billinger et al., 2014), duration ( $<3$ months or $\geq 3$ months), procedures for control group (physiotherapy or standard care without extra exercise intervention). The trials employing high intensity training [defined as exercise with maximal or near maximal heart rate or oxygen uptake Bonsu and Terblanche, 2016; Riebe, 2018] were excluded as recent evidence uncovered different impacts this special mode could exert on cardiovascular disease risks from aerobic training (Hasegawa et al., 2018). We then investigated the moderating effect of measurement used (subjective or objective). We also limited the disease type to stroke to uncover effects of aerobic exercise on global cognitive function and did the subgroup analysis based on the starting point of intervention poststroke ( $<3$ months or $\geq 3$ months). In the meantime, change of specific domains of cognition before and after aerobic exercise was explored, including processing speed and executive function. The latter was further divided into response inhibition, set shifting and working memory. A $p$ value $<0.05$ was considered statistically significance. Inconsistency between subgroups was shown in terms of $I^{2}$ statistic in the forest plot.

\section{RESULTS}

\section{Characteristics of Included Studies}

The selection process is summarized in the PRISMA study flow diagram (Figure 1). The initial search returned 1,522 potentially relevant citations and was reduced to 1,382 following duplicates removal. A total of 80 articles were retrieved for fulltext review. There were two studies producing more than one publication (Tang et al., 2014, 2016; Liu-Ambrose et al., 2016; Hsu et al., 2017, 2018; Dao et al., 2019; Khattab et al., 2019), they were regarded as one study in the quantitative analysis. One publication (Rosenfeldt et al., 2019) was the secondary analysis of two randomized controlled trials (ClinicalTrials.gov registration numbers NCT02076776, National Institutes of Health, and NCT02494518, American Heart Association). As it was the only publication relevant to the two trials and provided more data interested than that on the official webpage of ClinicalTrials.gov, we considered the two trials as one study. Finally, 11 studies were included in the quantitative analysis, representing data from 


\section{PRISMA 2009 Flow Diagram}
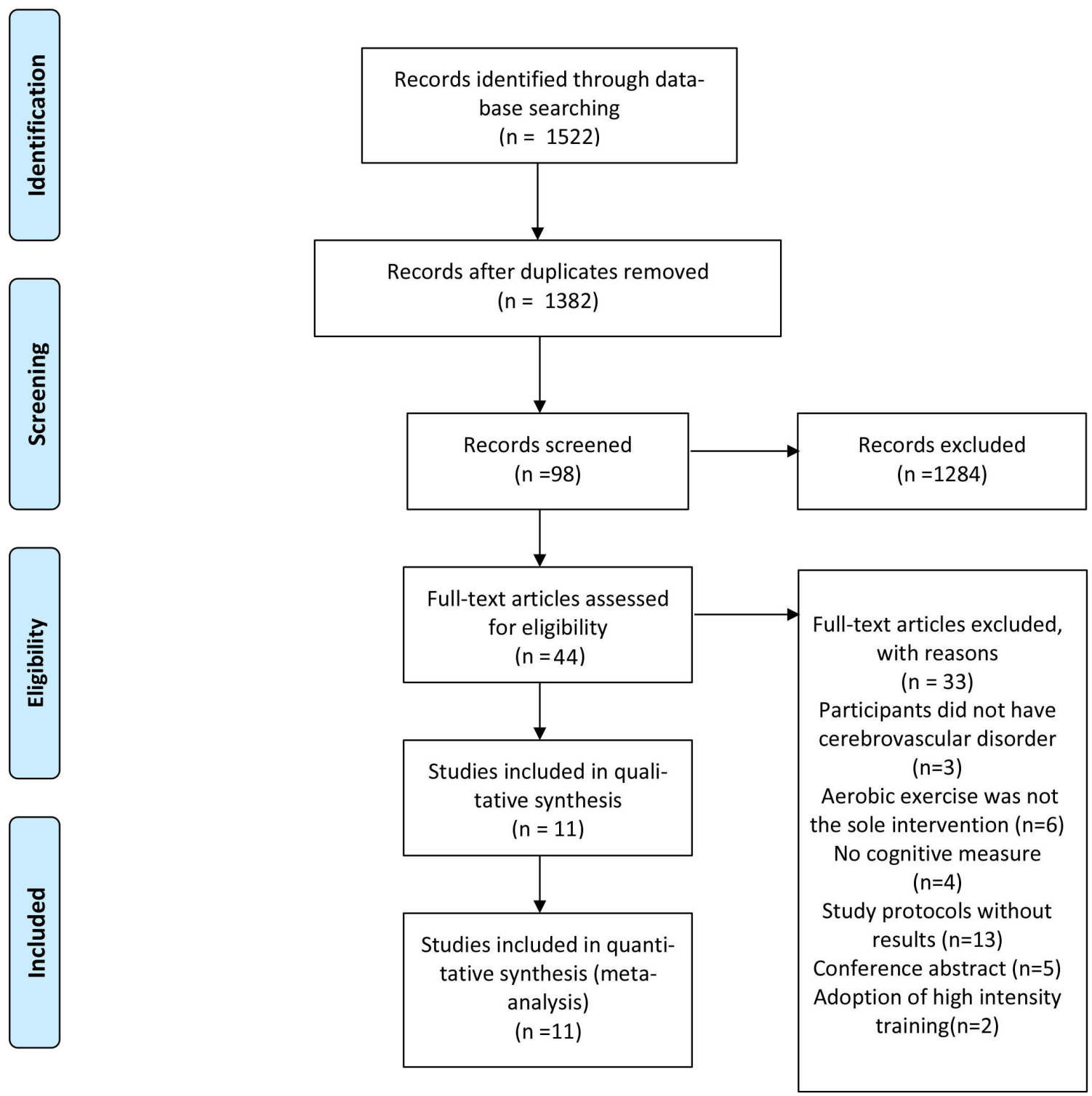

From: Moher D, Liberati A, Tetzlaff J, Altman DG, The PRISMA Group (2009). Preferred Reporting Items for Systematic Reviews and Meta-Analyses: The PRISMA Statement. PLoS Med 6(7): e1000097. doi:10.1371/journal.pmed1000097

For more information, visit www.prisma-statement.org.

FIGURE 1 | PRISMA flow chart of study selection process. 
1,038 participants. Studies were published between November 2009 and February 2020. Study sizes ranged from 30 to 362 and the average age was 71.58 . There was no significant difference in age between intervention (66.1; SD:12) and control groups (68.2; SD:10.8). Patients were diagnosed with stroke in 10 studies (Quaney et al., 2009; El-Tamawy et al., 2014; Liu-Ambrose et al., 2016; Tang et al., 2016; Ploughman et al., 2018; Bo et al., 2019; Debreceni-Nagy et al., 2019; Ihle-Hansen et al., 2019; Nave et al., 2019; Rosenfeldt et al., 2019) and with small vessel ischemic disease in the rest one (Liu-Ambrose et al., 2016). Among the aerobic exercise interventions, one study maintained participants' heart rate reserve (HRR) below 40\% (DebreceniNagy et al., 2019) and three studies adopted moderate intensity training (El-Tamawy et al., 2014; Liu-Ambrose et al., 2016; Nave et al., 2019). The remaining studies adopted vigorous intensity intervention. Except for the trial done by Ihle-Hansen et al., the training frequency was three or five times per week. IhleHansen and his colleagues adopted the strategy to perform the vigorous exercise once a week with a 30 -min physical activity every day. The entire program lasted for 1-18 months. The baseline information and methodological characteristics of these studies are summarized in Tables 1, 2.

\section{Quality Assessment}

The quality assessment is summarized in Figure 2. Nearly half of the studies did not report the method of sequence generation and allocation concealment and were judged to have an unclear risk of bias in these two regions. In all studies assessed, it was impossible to blind participates and therapists. Among them, six studies were judged that the outcome was unlikely to be interfered by absence of blinding. All studies gave information about drop-out and thus were considered having a low risk of bias in outcome reporting. Other domains were judged having a low risk of bias.

\section{Effects of Aerobic Exercise on General Cognitive Function}

Using data from seven studies, we first investigated whether patients with ischemic cerebrovascular disorder benefited from aerobic exercise in global cognitive function relative to controls. Results indicated a positive but not significant effect of aerobic exercise on general cognition $(0.13 ; 95 \% \mathrm{Cl}-0.09$ to $0.35 ; p=$ 0.25 ; Figure 3$)$. The assumption of homogeneity was valid among the studies $\left[\mathrm{Chi}^{2}=9.72, \mathrm{df}=6(p=0.14) ; I^{2}=38 \%\right]$. There was no significant change when any one of the study was removed. We then did the subgroup analysis based on exercise intensity. The findings revealed that training with moderate intensity could bring along cognitive benefits $(0.34 ; 95 \% \mathrm{Cl}-0.01$ to $0.69 ; p=$ 0.06; Figure 4) while the performance in the vigorous-intensity group was less fascinating $(0.01 ; 95 \% \mathrm{Cl}-0.19$ to $0.22 ; p=0.9)$. Nevertheless, there was no significant subgroup differences [Chi ${ }^{2}$ $\left.=3.4, \mathrm{df}=2(p=0.18) ; I^{2}=41.2 \%\right]$.

We also did subgroup analysis to explore whether baseline cognitive status exerted impacts on cognitive improvement. It was observed that patients already with cognitive impairment (312 participants) embraced significant cognitive benefits from aerobic exercise $(0.31 ; 95 \% \mathrm{Cl} 0.07-0.55 ; p=0.01$; Figure 5), while the effect size in patients with healthy baseline cognitive status (374 participants) failed to show this merit $(-0.05 ; 95 \%$ $\mathrm{Cl}-0.26$ to $0.16 ; p=0.64)$. And there was significant difference between subgroups [Chi ${ }^{2}=5.03, \mathrm{df}=1(p=0.02) ; I^{2}=80.1 \%$ ].

In the studies lasting for more than 3 months (359 participants), one study went on for 6 months and the other lasted for 18 months. Among the studies lasting for $<3$ months (327 participants), one lasted for 2.5 months, two lasted for 2 months, and the rest two lasted for 1 month. Both subgroups showed positive but not significant gains in global cognition (Figure 6). The effect size of shorter duration was larger. There was no significant difference between subgroups $\left[\mathrm{Chi}^{2}=0.83\right.$, df $\left.=1(p=0.36), I^{2}=0 \%\right]$.

Meanwhile, we also investigated the influence of different control conditions on cognition improvement after aerobic exercise. Four of the seven studies gave participants in control group physiotherapy (for example, stretching exercise) for alternative (287 participants) while the rest were only provided with usual care (e.g., education material without special focus on physical training, 399 participants). Results indicated that the adoption of physiotherapy or education program for control group was not the variant affecting the cognitive consequence [test for subgroup difference: $\mathrm{Chi}^{2}=2.25, \mathrm{df}=1(p=0.13), I^{2}=$ 55.6\%; Figure 7].

Moreover, we investigated whether subjective measurement would show variable consequence compared to objective measurement. We did not find significant difference between subgroups $\left[\mathrm{Chi}^{2}=0.25, \mathrm{df}=1(p=0.62) ; I^{2}=0 \%\right.$; Figure 8]. Statistically homogenous was met in all subgroups.

When the type of disease was restricted to stroke, cognitive gains were also positive but not significantly different from zero (0.08; $95 \% \mathrm{Cl}-0.08$ to $0.25 ; p=0.31$; Figure 9). We further investigated whether starting time of intervention poststroke exerted impacts on cognition. Among the 2 studies launched within 3 months poststroke (468 participants), one included patients who were 3 months post stroke and the other began 545 days ( $28.51 \pm 17.24$ days) after the occurrence. Results showed no significant between group difference $\left[\mathrm{Chi}^{2}=1.09, \mathrm{df}=1(p\right.$ $\left.=0.30) ; I^{2}=8.6 \%\right]$.

\section{Effects of Aerobic Exercise on Processing Speed and Executive Function}

We also examined changes on special cognitive domains. The study of Debreceni-Nagy et al. reported results of two subtests of processing speed (coding subset and symbol search sum score) (Debreceni-Nagy et al., 2019). We applied the symbol search sum score in Figure $\mathbf{1 0}$ and the finding was similar if the coding subset was adopted. No significant between group difference was found in processing speed $(0.12 ; 95 \% \mathrm{Cl}-0.05$ to $0.29 ; p=0.18)$. Response inhibition, set shifting and working memory were three important aspects of executive function. However, none of these aspects showed significant difference from zero (Figures 11-13).

\section{DISCUSSION}

Our results suggested that aerobic exercise might improve cognitive function in patients with ischemic cerebrovascular 
TABLE 1 | Characteristics of included studies.

(male/female) and drop-out

Debreceni-Nagy With the age of 18 75;

et al. (2019) ischemic or haemorrhagic stroke more than 3 month ago; no dementia (MMSE score $>23$ )

El-Tamawy et al.

Egyptian stroke patients with strokes in the territory of anterior circulation; time interval between stroke occurrence and intervention initiation ranging from 3 to 18 months; cognitive inpairment (ACER score $<82$ )

*Ihle-Hansen et al. Aged over 18; first- ever or (2019) recurrent stroke (infarction or intracranial haemorrhage), 10-16 weeks post the occurrence;

community-dwelling with

modified Rankin Scale score $<5$, MMSE $\geq 21$ (or $\geq 17$ for patients with aphasia)

\#Liu-Ambrose et al. Aged over 18; with diagnosis of small vessel ischemic

Intervention $=19(13 / 6)$, one withdrew consent and one died because of pulmonary embolism during a resting, weekend day Control $=16(11 / 5)$, no drop-out

Intervention $=15(11 / 4)$, no drop-out; Control $=15(10 / 5)$, no drop-out

disease; cognitive impairment score $\geq 20$ )

ervention $=35(16 / 19)$, two thdrew and the other one failed

Intervention $=177$ (99/78), nine died; Control = 185(120/65), nine died. The death was no correlation with the intervention

finish the cognitive assessment:

A 60-min class including a 10-min warm-up, a 40-min walk,

"Nave et al. (2019) Aged over 18; ischemic or hemorthagic stroke survivo 5 45 days after stroke occurrence; Barthel index score $\leq 65$

Intervention $=105(60 / 45)$, two were excluded before training, one violated the strategy, five had severe adverse event, four had adverse event, four were transferred to oth clinic, four refused to participate; Control $=95(59 / 36)$, one violated the strategy, one stopped training more than 5 days after initiation,

three had severe adverse event, one had adverse event, one refused to participate, four were transferred to other clinic and a 10-min cool down. The training intensity was monitored based on the measure of HRR (progressing from 40 to $60 \sim 70 \%$ in first 12 weeks and maintaining at $65 \%$ ), RPE (14 15), "talk" test (a pace at which conservation was difficult). The intervention was instructed and class attendance was recorded

Control

Cognitive outcome(s)

A conventional, customized physiotherapy for $30 \mathrm{~min}$

ollowed by a bicycle training for $30 \mathrm{~min}$ including a warm-up

$(5 \mathrm{~min})$, a therapy $(20 \mathrm{~min})$, maintenance of target heart rate

and a cool-down $(5 \mathrm{~min})$ phase. HRR was maintained

cosecutive weekdays

A designed physiotherapy program consisting of stretching exercises, facilitation for weak muscles, strengthening

exercise, postural control and balance, functional training an

It was followed by a rest for $10 \sim 15 \mathrm{~min}$ and then a bicycle

training for 40 45 min including a warm-up (5 10 min), an

active phase (30 $\mathrm{min})$ and a cool-down $(5 \mathrm{~min})$. The program

was considered moderate intensity and was performed three

instructed by a qualified physiotherapist

A 45-60 min physical exercise including 2-3 bouts of

vorous activity (15-17 on the Borg scale of perceived

xertion) every week and 30-min-physical activity 7 days



observed training but the amount and intensity of each day's

activities were recorded. The program lasted for 18 months

Standard care

obal cognitive function

(MMSE), processing speed

(TMT-A), set-shifting (TMT-B)

Usual care as well as monthly

educational materials about vascular

Global cognitive function

(ADAS-Cog), performance of

daily living (ADCS-ADL), globa

executive function (EXIT-25),

response inhibition (Stroop Test),

working memory (verbal digit

span tests, digits forward minus

digits backwards), set shifting

(TMT, part B minus part A)

A therapist led session for $50 \mathrm{~min}$, including $25 \mathrm{~min}$ of core tervention (training aimed at target heart rate). The training was treadmill based with bodyweight support. The intens was maintained at $50 \sim 60 \%$ of maximum heart rate. The

A therapist led session for $50 \mathrm{~min}$,

Global cognitive function

(MoCA); processing speed (TMT

The core part focused on contraction A); set shifting (TMT B)

and relaxation of muscle groups in th

face, arms, shoulders, back, and

abdomen. The intervention was

4 weeks. The training was monitored

and duration and was also monitored
Global cognitive function (FIM speed (Symbol Search and working memory (WAISIV, Digit

Global cognitive function (ACER) 
*Ploughman et al. Aged over 18; ischemic or

(2019) hemorrhagic stroke $>6$
months; able to perform months; able to perfom two-step instruction, ambulation with/without aid $\geq 10 \mathrm{~m}$, without high-risk self-reported cognitive problems related to stroke interfering with daily functioning but without moderate/severe receptive

aphasia

\#Quaney et al. Chronic stroke survivors $\geq 6$ (2009) months prior to the intervention); with residua intervention), which residual the paretic deficts in either the upper or lower extrenty MMSE $>23$

*Rosenfeldt et al. Aged 18 85; single, unilatera (2019) Chronic stroke survivors $(\geq 6$ months prior to intervention); Fugl-Meyer Motor Score 19 55 in involved upper extremity

\#Tang et al. (2014) Aged 50-80; >1 year post-stroke, completing post-stroke, completing the rehabity and able to the communily, and able to walk $5 \mathrm{~m}$ independently $w$ th or without assistive devices

"Bo et al. (2019) Aged over 18; <6 months post-stroke; without severe somatic diseases or menta somatic dis whenta disorders, without visual or auditory disturbances in diagnostic criteria for vascula cognitive impairment (criteria cognitive impairment (criteria
from National Institute of from National Institute of Neurological Disorders and
Stroke-Canadian Stroke Network)
Intervention $=25$ (16/9), Control $=\quad$ Aerobic exercise performed on a treadmill with body weight $27(20 / 7)$. three unable to secure $27(20 / 7)$. three unable to secure comply wh time requir unable to comply wh time requirement, refusing group assignment support and target heart rate zone corresponding to of peak oxygen uptake $\left(\mathrm{VO}_{2 \text { peak }}\right)$. The program was instructed. nterventions designed to improve

ntervention = 19(10/9); Control $=19(7 / 12)$ Two patients dropped after enrollment and were not included in the analysis A 55-min session including a 5-min warm-up, a 45-min cool-down. In


maximum heart rate in the $70 \%$ maximum hear rate. It was peformed three times per week for 8 weeks under the physician's supervision A 45-min cycling consisting 5-min warm-up,35-min main Intervention $=32(22 / 10)$, one dropped out with poor skin integrity three with non-compliance, one with recurrent stroke; Control $=8(7 / 1)$ one dropped with non-compliance and two with unrelated injury Intervention $=25(14 / 11)$, three dropped out; Control $=25(15 / 10)$ no drop-out e set, and a 5-min cool-down. HRR was maintain $60 \sim 80 \%$. The aerobic exercise was also combined with a 45-min upper extremity repetitive arm exercises. It was conducted three times per week for 8 weeks. Heart rate was continuously monitored.

Exercise including 10-min warm up, 0 40 min aerobic

component and 10-min cool down. Training modes included brisk level and inclined overground walking, upright and recumbent cycle ergometry, and non-traditional forms of exercise utilizing functional movements, such as marching-on-the-spot, repeated sit-to-stand, and step-ups onto platform steppers. The intensity progressed to $58.1 \%$ HRR and RPE 14.2 (a little bit hard to moderate) by the end of the intervention. The program was conducted three times per week for 6 months. The intervention was instructed Exercise including a 5-10 min warm-up period of aerobic

ntervention $=86(50 / 39), 25$ dropped out, 13 declined, 12 felt unwell; Control = 91(52/39), 21 dropped out; 9 declined, 13 fet unwell; the exclusion had no correlation with the intervention exercise, such as jogging or cycling, followed by the main component (30-35 $\mathrm{min}$ ) of endurance, strength, and balance exercise, ending with a 5-min cool-down of stretching and exercises to recover normal cardiac levels. The intensity was maintained at the moderate intensity level with the Borg scale of 13-15. The program was performed three times per week, lasting for 12-weeks. Participants' heart rates were monitored throughout the session 8 or 8 wers $(24$ sesions) 3 ther week
Therapeutic activity includin ange of motion and comfort of the affected side (massage and active and passive range of motion exercises) an to relearn routine mobility tasks such as lying to sitting, rolling, sit to stand and standing balance (functional task training)

Global cognitive function (Fluid Intelligence)

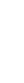

45-min upper and lower extremity stretching or 8 weeks ( 24 sessions) at hor w participants about exercise questions every week

A 45-min session of stroke-related education followed by an identical 45-min session of upper extremity repetitive arm exercises, with equivalent frequency and duration

Stretching, weight bearing, postural awareness and balance exercises with $\mathrm{HRR}<40 \%$ and with equivalent frequency and duration Response inhibition (Color-Word (The Verbal Digit Span Backwards Test); set shifting (TMT B)

Usual care and a 45-min video documentaries three times per week

Spatial imagination (The mental rotation test), response inhibition (Stroop test), working memory (Digit Span Test- Forward), set shifting (TMT-B)

ACER, Addenbrooke's Cognitive Examination-Revised; ADAS-Cog, Alzheimer's Disease Assessment Scale-Cognitive section; ADCS-ADL, Alzheimer's Disease Cooperative Study-Activities of Daily Living; EXIT, executive interview; HIT, high intensity training; HIIT, high intensity interval training; HRR, heart rate reserve; MoCA, Montreal Cognitive Assessment; MMSE, Mini -mental State Examination; RPE, Borg Rating of Perceived Exertion; SIS, Stroke Impact Scale; SSS, Scandinavian Stroke Scale; TMT, Trail- Making Tests; WAIS-IV, Wechsler Adult Intelligence Scale-Fourth Edition; WCST, Wisconsin Card Sorting Task.

*The number of participants refers to the number of participants accomplishing post-intervention assessment.

\#The number of participants refers to the number of participants receiving the intervention. 
TABLE 2 | Comparisons of participants" characteristics at baseline.

\begin{tabular}{|c|c|c|c|c|c|c|c|c|}
\hline & $\begin{array}{c}\text { Age } \\
\text { Mean (SD) }\end{array}$ & $\begin{array}{l}\text { Characteristic of the cerebral } \\
\text { infarction involved }\end{array}$ & Basic information & $\begin{array}{l}\text { Baseline physical strength } \\
\text { and movement function }\end{array}$ & $\begin{array}{l}\text { Baseline Cognitive } \\
\text { Function }\end{array}$ & $\begin{array}{l}\text { Other neurological } \\
\text { and/or psychological } \\
\text { condition/deflects }\end{array}$ & Comorbid Conditions & Other \\
\hline $\begin{array}{l}\text { Debreceni- } \\
\text { Nagy et al. } \\
\text { (2019) }\end{array}$ & $58.7(11.2)$ & $\begin{array}{l}\text { Months post occurrence, mean } \\
\text { (SD):11.4 (13.7); stroke type, } \\
\text { ischemic/hemorrhagic:11/7; } \\
\text { Times of involvement, } \\
\text { first/recurrent stroke, } n: 29 / 6 \text {; } \\
\text { Hemisphere involved, dominant } \\
\text { side, } n: 17 \text {; Stroke severity, } \\
\text { NIHSS, mean (SD): } 3.4 \text { (2.1) }\end{array}$ & $\begin{array}{l}\text { BMI, mean (SD): } \\
27.8 \text { (4.6); }\end{array}$ & $\begin{array}{l}\text { Walking independently, } n: 20 \text {; } \\
\text { Aerobic fitness (VO2max) } \\
\text { (mL/kg/min) mean (SD):12.6 } \\
\text { (4.8); }\end{array}$ & $\begin{array}{l}\text { MMSE, } \\
\text { mean(SD):27.9(1.4) }\end{array}$ & Motor aphasia,n:3; & $\begin{array}{l}\text { Cardiovascular disorder, n: } \\
14\end{array}$ & $\begin{array}{l}\text { Sedentary lifestyle } \\
\text { (physical activity } \leq \\
3 \times 30 \mathrm{~min} / \text { week) } \\
\text { n:32; }\end{array}$ \\
\hline $\begin{array}{l}\text { El-Tamawy } \\
\text { et al. (2014) }\end{array}$ & $49.0(6.6)$ & $\begin{array}{l}\text { Months post occurrence: range } \\
\text { from } 3 \text { to } 18 \text { months }\end{array}$ & $\begin{array}{l}\text { BMI, mean (SD): } \\
25.5(2.0)\end{array}$ & - & $\begin{array}{l}\text { ACER Score, mean(SD): } \\
74.0(5.8)\end{array}$ & - & - & - \\
\hline $\begin{array}{l}\text { Ihle-Hansen } \\
\text { et al. (2019) }\end{array}$ & $72(11.6)$ & $\begin{array}{l}\text { Days post stroke, mean (SD): } \\
111.7 \text { (21.1); Stroke type, } \\
\text { ischemic/hemorrhagic, } n: 346 / 34 \text {; } \\
\text { Stroke severity, NIHSS, mean (SD): } \\
1.6 \text { (2.4); Previous stroke, } n: 29 ;\end{array}$ & - & $\begin{array}{l}\text { Motor Assessment Scale, mean } \\
\text { (SD): } 41.8 \text { (7.1); Barthel index, } \\
\text { mean (SD): } 96.2 \text { (0.8); Berg } \\
\text { Balance Scale, mean (SD): } 2.5 \\
\text { (1.4); Timed Up and Go test(s), } \\
\text { mean (SD): } 14.2 \text { (23.1); 6-min } \\
\text { walk test(m), mean (SD): } 390.1 \\
(204.3)\end{array}$ & $\begin{array}{l}\text { MMSE, mean(SD): } \\
27.8(2.5)\end{array}$ & - & $\begin{array}{l}\text { Transient ischemic attack, } \\
\text { n:38; Myocardial } \\
\text { infarction, n:47; Heart } \\
\text { failure, n:9;Atrial fibrillation, } \\
\text { n:75; Hypertension, n:199; } \\
\text { Diabetes mellitus, n:54; } \\
\text { Lung diseases, n:44 }\end{array}$ & - \\
\hline $\begin{array}{l}\text { Liu-Ambrose } \\
\text { et al. (2016) }\end{array}$ & $74.3(8.3)$ & $\begin{array}{l}\text { Sub-cortical ischemic cognitive } \\
\text { impairment }\end{array}$ & $\begin{array}{l}\text { Weight(kg), mean } \\
\text { (SD): } 71.2(14.2) ; \\
\text { BMI, mean (SD): } \\
25.9 \text { (3.8); Resting } \\
\text { heart rate, mean } \\
\text { (SD): } 68.6 \text { (13.8); } \\
\text { Resting systolic } \\
\text { blood pressure } \\
\text { (mmHg), mean } \\
\text { (SD): 136.0 (18.5); } \\
\text { Resting diastolic } \\
\text { blood pressure } \\
\text { (mmHg), mean } \\
\text { (SD): } 78.5(10.8)\end{array}$ & $\begin{array}{l}\text { Functional comorbidity index, } \\
\text { mean (SD): } 2.8 \text { (1.9); 6-Min Walk } \\
\text { Test (m), mean (SD): } 494.9 \\
(97.8) ; \text { Physical activity scale for } \\
\text { the elderly, mean (SD): } 121.5 \\
(64.7)\end{array}$ & $\begin{array}{l}\text { MMSE, } \\
\text { mean(SD):26.4(2.9); } \\
\text { MoCA, } \\
\text { mean(SD):21.2(3.9),ADAS, } \\
\text { cognition, } \\
\text { mean(SD):11.0(5.5) }\end{array}$ & & Hypertensive, n:37; & $\begin{array}{l}\text { Education (> high } \\
\text { school), n:51; waist } \\
\text { to hip ratio, } \\
\text { mean(SD):0.9(0.08) }\end{array}$ \\
\hline $\begin{array}{l}\text { Nave et al. } \\
\text { (2019) }\end{array}$ & $69(12)$ & $\begin{array}{l}\text { Days post stroke, mean (SD): } 28.5 \\
\text { (17.2); Stroke type, } \\
\text { ischemic/hemorrhagic, } n: 181 / 9 ; \\
\text { Anterior circulation stroke, } n: 156 ; \\
\text { Stroke severity, NIHSS, mean } \\
\text { (SD): } 8.2 \text { (4.9); Previous stroke, } \\
n: 27 \text {; Cause of ischemic stroke, } n \text { : } \\
\text { large artery atherosclerosis (17), } \\
\text { cardioembolism (18), small vessel } \\
\text { occlusion (16), other causes (3), } \\
\text { undetermined causes (34), } \\
\text { competing causes (3) }\end{array}$ & - & $\begin{array}{l}\text { Maximal walking speed (m/s), } \\
\text { mean (SD): } 0.5(0.4) ; \text { Barthel } \\
\text { index score, mean (SD): } 48.0 \\
\text { (16.5); 6-Min Walking } \\
\text { distance(m), mean (SD): } 122.2 \\
(112.3)\end{array}$ & $\begin{array}{l}\text { MoCA, mean(SD): } \\
23.2(5.7)\end{array}$ & $\begin{array}{l}\text { Depression (measured by } \\
\text { CES-D), } \\
\text { mean(SD):10(6.1); }\end{array}$ & - & - \\
\hline
\end{tabular}


ACER, Addenbrooke's Cognitive Examination-Revised; BMI, body mass index; CES-D: Center for Epidemiologic Studies depression scale; HADS-D, Hospital Anxiety and Depression Scale-Depression subscale; MMSE, Mini-Mental State Examination; MoCA, Montreal Cognitive Assessment; NIHSS, National Institutes of Health Stroke Scale; PSQI, Pittsburgh sleep quality index; $V_{2}{ }_{2}$ max, maximum oxygen intake. 




FIGURE 2 | Risk of bias analysis in accordance with Cochrane Handbook.

disorder. Particularly, moderate intensity aerobic training might be the most promising mode to alleviate or prevent vascular cognitive impairment. Population already with cognitive impairment were suggested to benefit more from aerobic training compared to their cognitively healthy counterparts.

A previously published meta-analysis demonstrated a significant and moderate improvement in cognition after physical activity in stroke survivors (Oberlin et al., 2017). However, only 3 studies using aerobic exercise as the sole intervention were available in that study. A systematic review limited the intervention to aerobic exercise and suggested its positive effects on cognition post stroke (Zheng et al., 2016). However, the research team of this analysis also included studies where interventions like yoga, tai, and chi were employed. In our study, stricter criteria were employed to ensure that aerobic exercise was the sole intervention. We also investigated the influence of exercise intensity, duration, and starting point poststroke on cognitive gains, which might better guide future clinical practice. Specific domains including processing speed and executive function were studied, providing a deeper and broader sight into this issue.

Previous meta-analysis failed to find any significant improvement in global cognition after aerobic exercise in healthy old adults (Young et al., 2015; Sanders et al., 2019). However, population suffering from cognition impairment were suggested positively benefited from this intervention (Song et al., 2018; Sanders et al., 2019). Similarly, in our study, better improvement was observed in cognitively defective group. Aerobic exercise benefits cognition probably through the up-regulation of growth factors including BDNF, IGF1, and VEGF, promoting neurogenesis and angiogenesis, especially in hippocampus (Cotman et al., 2007). Evidence suggested that the concentration of BDNF was positively correlated with Barthel index scores, a measure of ability for daily living. BDNF was also relevant to the concentration subscale of Mini-mental State Examination (MMSE) score despite no close association found between BDNF concentration and total MMSE score (Navarro-Martínez et al., 2015). IGF-1 was suggested as the possible biomarker of cognition and the decline of this molecule was related to cognitive impairment (Frater et al., 2018). In the model of vascular cognitive impairment, IGF-1 and IGF-1 mRNA were found downregulated in hippocampus (Gong et al., 2012). It has also been found in animal model that the inhibition of VEGF receptor would induce neurological injury, limiting the excretion of BDNF (Chen et al., 2019). It is possible that the reduction of these important growth factors in cognitively impaired participants makes them show greater responsiveness to aerobic exercise.

For stroke survivors, exercise with an intensity of $40-70 \%$ HRR or $50-80 \%$ maximum heart rate is recommended (Billinger et al., 2014). Our results showed that aerobic exercise with moderate intensity was the most promising mode to promote global cognitive gains in patients with ischemic cerebrovascular disorder. The study included using low intensity intervention (Debreceni-Nagy et al., 2019) did not show significant difference from zero. Several researches have revealed that cognitive benefit derived from physical exercise is does-dependent. The underlying mechanism is that elevated exercise intensity is positively correlated with increase of BDNF and reduction of pro-inflammatory cytokines (Manuela Crispim Nascimento et al., 2014; Cefis et al., 2019). And light aerobic exercise may not be sufficiently intense to induce the changes. It is also worth considering that Debreceni-Nagy employed severely deconditioned patients in the program and used subjective measurement in his research, possibly resulting in less cognitive gain. In the meantime, although the effect size of general cognitive function was negative, Debreceni-Nagy found that of working memory and processing speed was positive. Recent study also indicate low-intensity training is beneficial for 




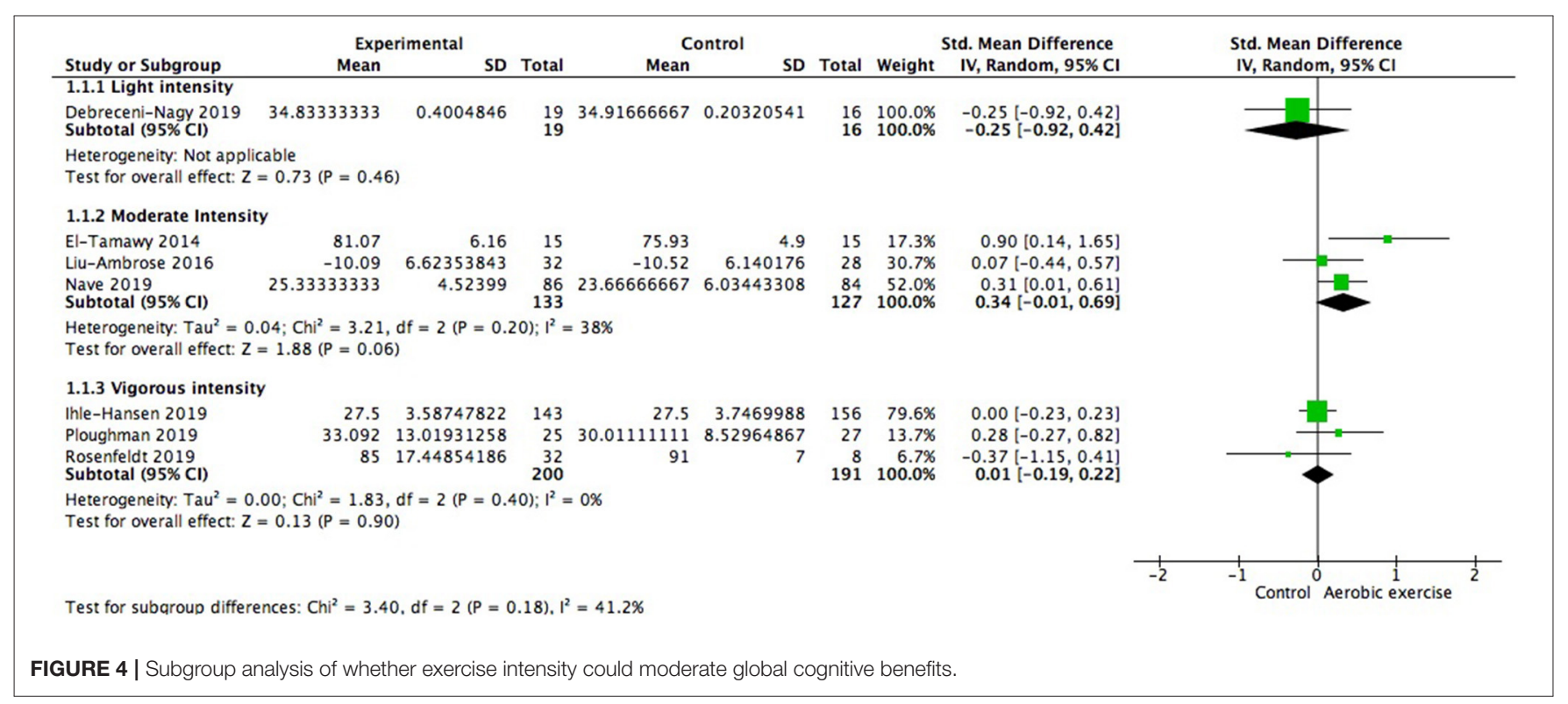

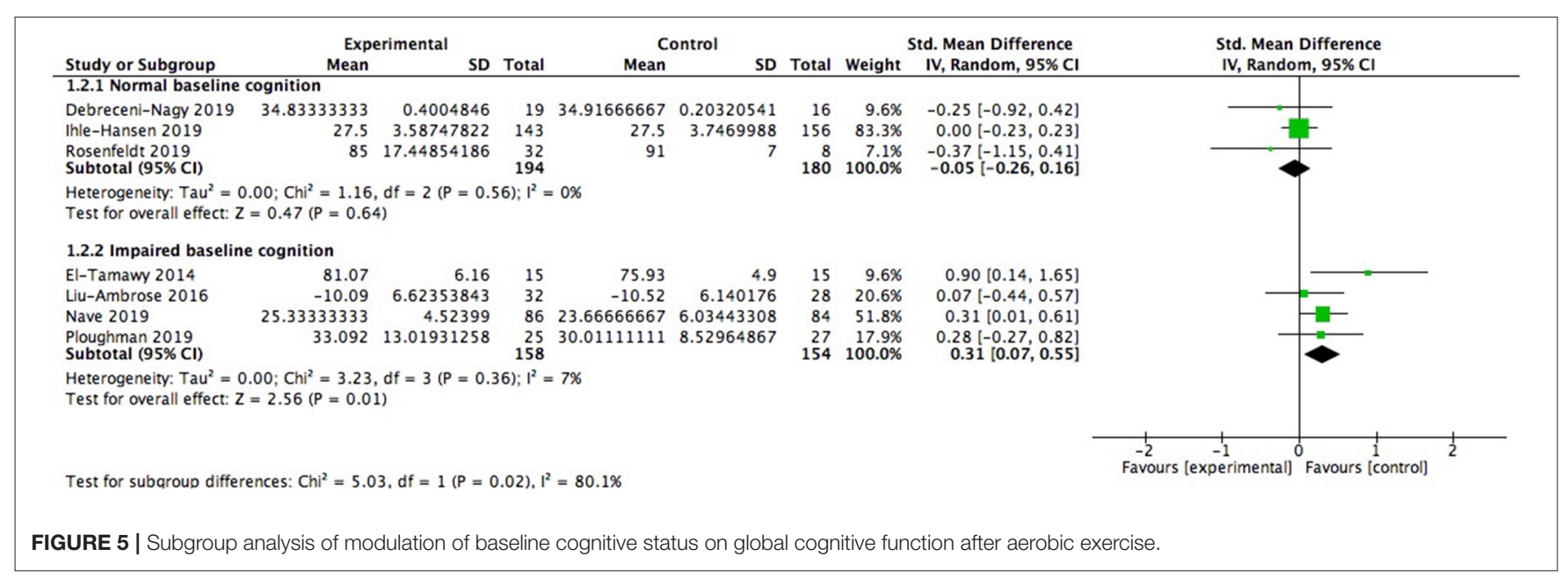

executive function and cortical excitability (Morris et al., 2020), so it is still recommended for the deconditioned survivors. However, in our analysis, vigorous-intensity exercise did not return cognitive benefits, either. The diversity of participants' performance might account for the insignificance. Patients with ischemic cerebrovascular disease are usually characterized with reduced cardiovascular fitness (MacKay-Lyons and Makrides, 2002) and impaired motor or balance ability (Askim et al., 2014). Consequently, they may fail to reach the targeted intensity to optimize its efficacy. When considering duration, longer program 


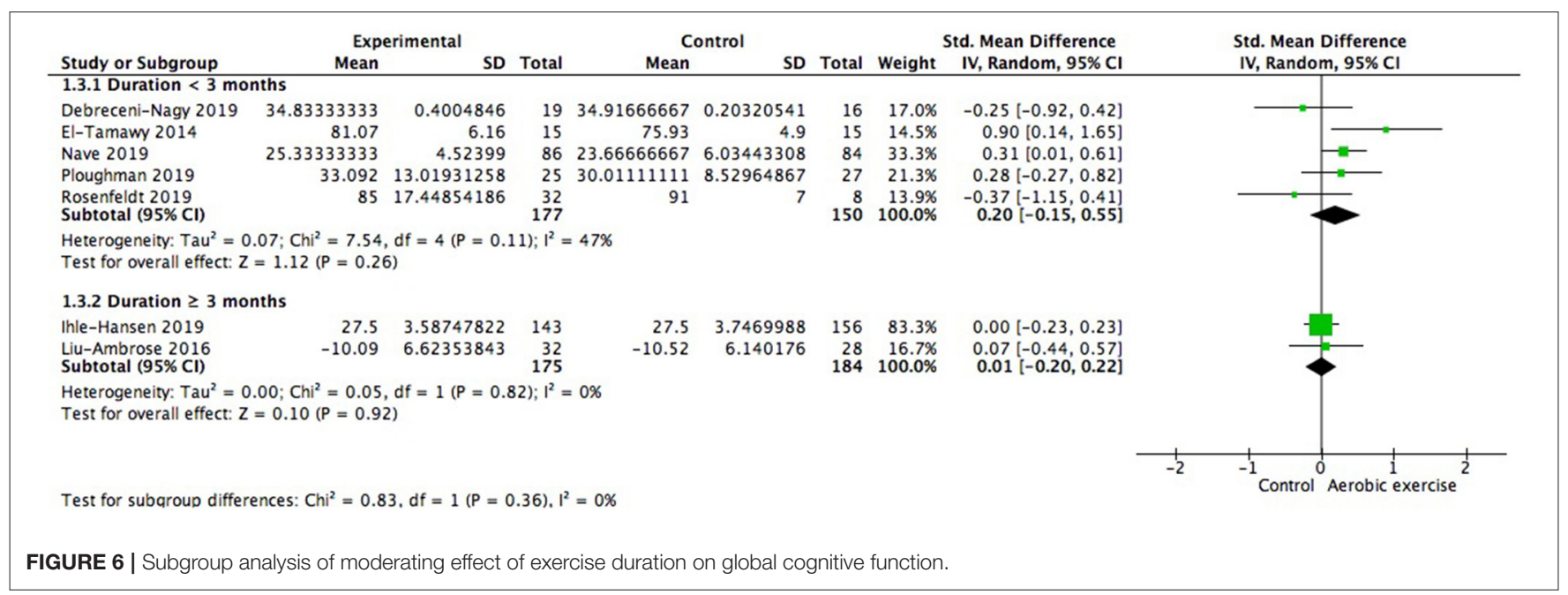

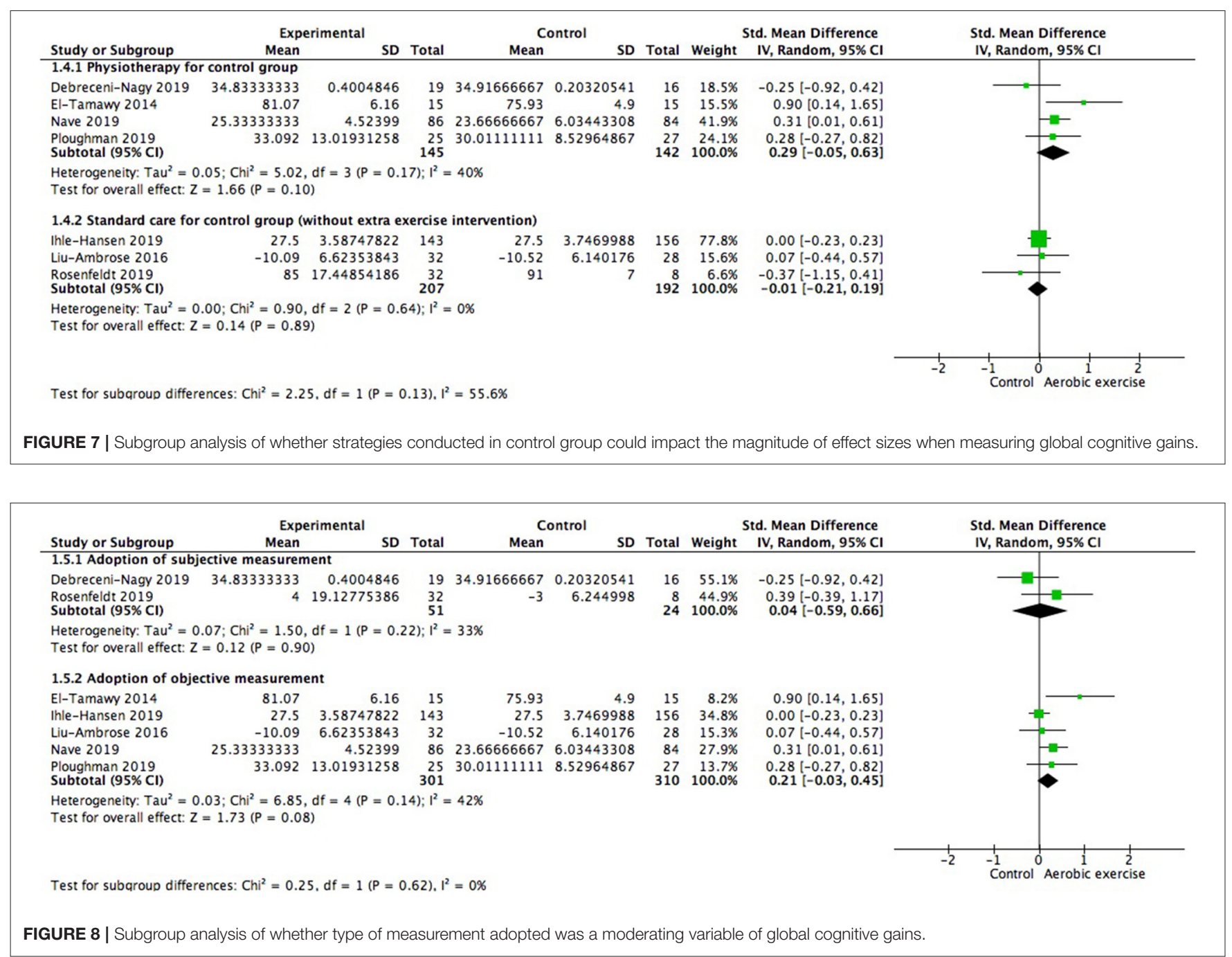

duration did not predict more cognitive gains. This finding is similar to a previous meta-analysis (Northey et al., 2018). The possible reason is that the compliance might decline as the project goes on. Ihle-Hansen's research also found increased adherence to the intervention was significantly associated with up-regulated MMSE scores (Ihle-Hansen et al., 2019). Therefore, 


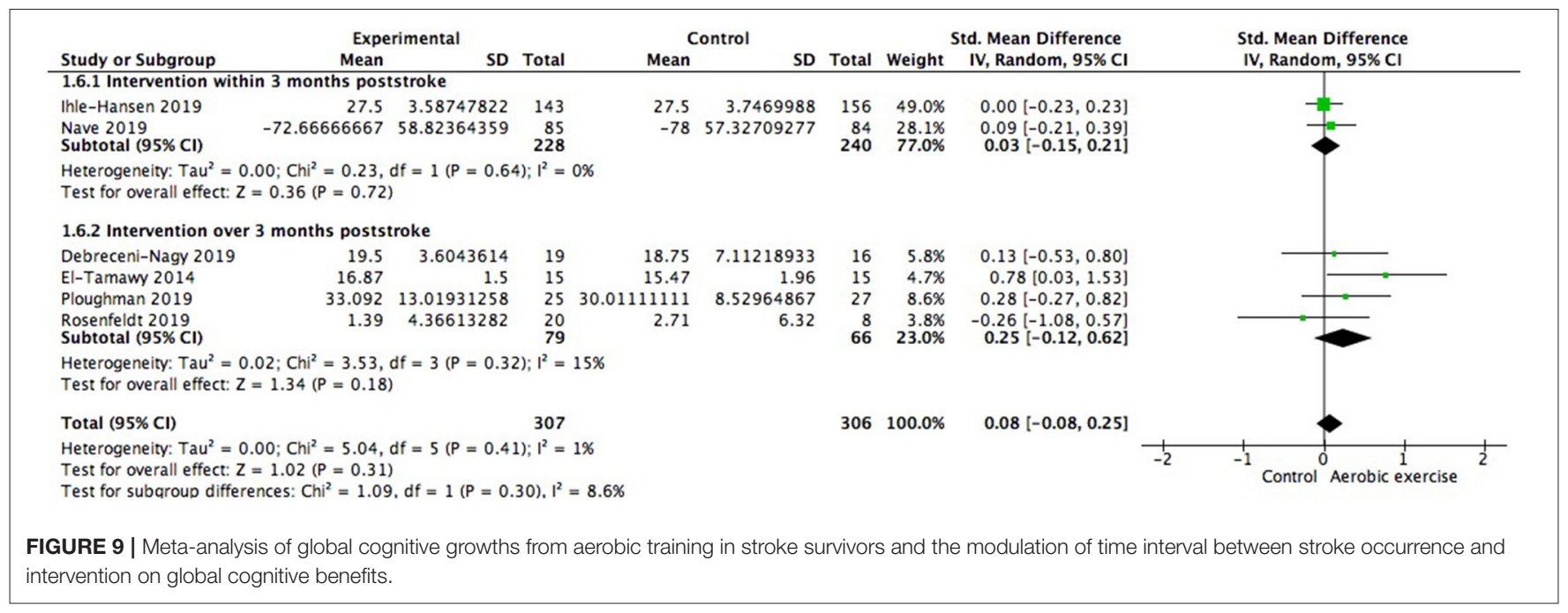



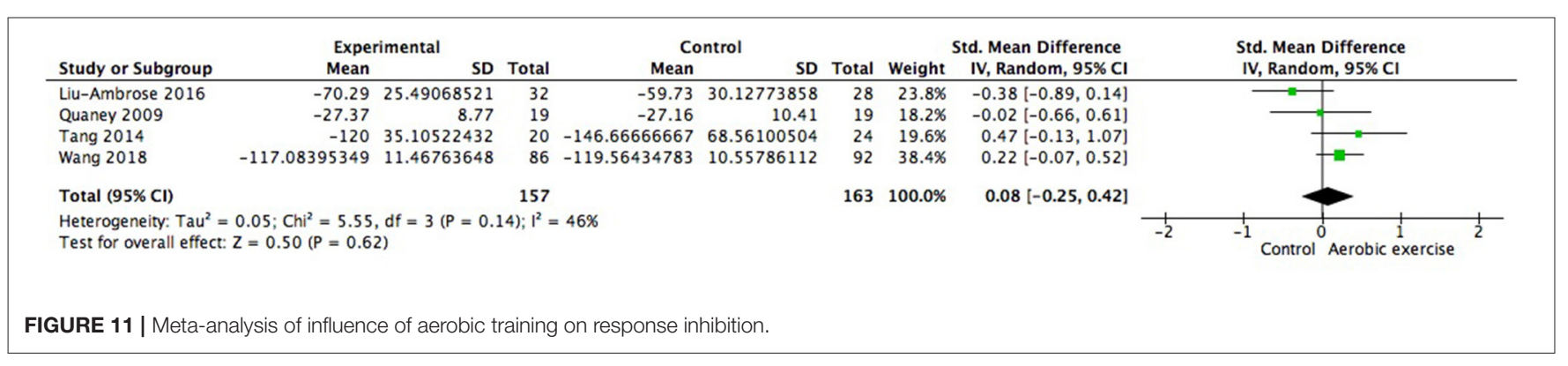

\begin{tabular}{|c|c|c|c|c|c|c|c|c|c|c|}
\hline Study or Subgroup & \multicolumn{2}{|c|}{ Experimental } & Total & \multicolumn{2}{|c|}{ Control } & Total & \multicolumn{2}{|c|}{$\begin{array}{cc}\text { Std. Mean Difference } \\
\text { Weight } & \text { IV, Random, } 95 \% \mathrm{CI}\end{array}$} & \multicolumn{2}{|r|}{$\begin{array}{l}\text { Std. Mean Difference } \\
\text { IV, Random, } 95 \% \mathrm{Cl}\end{array}$} \\
\hline Ihle-Hansen 2019 & -155.8 & 100.805357 & 108 & -161.3 & 120.59850745 & 101 & $39.8 \%$ & $0.05[-0.22,0.32]$ & & -1 \\
\hline Liu-Ambrose 2016 & -79.17 & 86.4113873 & 32 & -64.51 & 55.5599246 & 28 & $11.3 \%$ & $-0.20[-0.70,0.31]$ & & - \\
\hline Quaney 2009 & -67.68 & 53.83 & 19 & -57.05 & 46.41 & 19 & $7.2 \%$ & $-0.21[-0.84,0.43]$ & & \\
\hline Tang 2014 & -135.53333333 & 66.48044355 & 19 & -167.16666667 & 116.34548017 & 25 & $8.1 \%$ & $0.32[-0.28,0.92]$ & & \\
\hline Wang 2018 & -172.81953488 & 25.33940444 & 86 & -179.68532609 & 27.96425668 & 92 & $33.6 \%$ & $0.26[-0.04,0.55]$ & & $\rightarrow-$ \\
\hline Total $(95 \% \mathrm{Cl})$ & & & 264 & & & 265 & $100.0 \%$ & $0.09[-0.08,0.27]$ & & \\
\hline $\begin{array}{l}\text { Heterogeneity: } \operatorname{Tau}^{2}= \\
\text { Test for overall effect }\end{array}$ & $\begin{array}{l}=0.00 ; C h i^{2}=3.89 \\
Z=1.08(P=0.28\end{array}$ & df $=4(P=0.4$ & 42); $1^{2}=$ & $=0 \%$ & & & & & -1 & $\begin{array}{ccc}-0.5 & 1 & 0.5 \\
\text { Control Aerobic exericse }\end{array}$ \\
\hline
\end{tabular}

effort is needed to motivate the patients to engage in aerobic exercise in the long term. At present, no definite threshold has been found where the cognitive improvement of aerobic exercise could occur. Intensity, total duration, time for every session and frequency are all factors needed further exploration to reach the counterbalance for the optimal dose of exercise. In stroke 


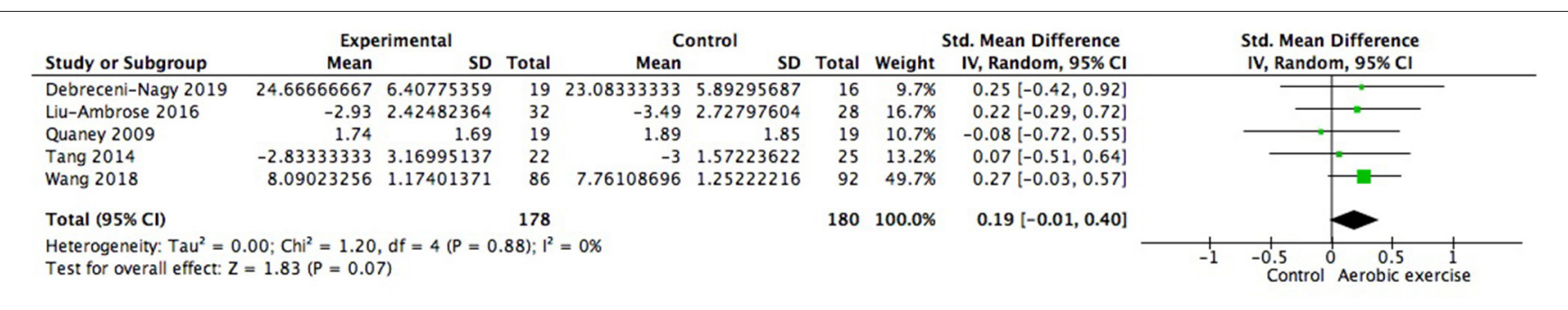

FIGURE 13 | Meta-analysis of effect of aerobic exercise on working memory.

survivors, the time point to initiate the exercise program was not the predictor of cognitive gains although the effect size of later intervention was greater. Pruski from Johns Hopkins proposed that the first 3 months post stroke were the most important period for recovery where most improvement could occur. And after 6 months, the progress would be much slower and reach a steady stage (Johns Hopkins Medicine, 2020). However, the stable condition and recovery of motor function may account for the benefits of late intervention. Moreover, the objective measurement might be the better choice when evaluating the cognitive gains, which is in line with the previous meta-analysis (Oberlin et al., 2017).

Processing speed refers to the time interval between sensory stimulus and related behavior response (Jensen, 2006). Previous trials indicated better aerobic endurance was correlated to improved processing speed and executive function in healthy old adults (Zettel-Watson et al., 2015). Aerobic exercise was also found beneficial for processing speed in patients with mild cognitive impairment (Zhu et al., 2018). In a study investigating multiple sclerosis, processing speed was positively associated with aerobic capacity which was indicated by $\mathrm{VO}_{2 \max }$ and balance (Sandroff and Motl, 2012). Also in multiple sclerosis, another study indicated that increased regional gray matter volumes in medial frontal gyrus, anterior cingulate cortex, and the precuneus were associated with the improved processing speed after aerobic exercise (Prakash et al., 2010). Executive function is a set of cognitive processes essential for behavior control to reach certain goals, for example, planning, organizing, coordinating and problem-solving (Diamond, 2013). Executive function relies on the integrity of prefrontal and parietal circuits (Colcombe and Kramer, 2003). Later report also demonstrated reduced gray volume in these regions in aged population and aerobic exercise could eliminate this aged-related deterioration (Colcombe et al., 2003). Another study demonstrated similar result as the cortical thickness increased in left caudal middle frontal area (Stern et al., 2017). Increased neural activity was also found in middle frontal gyrus, superior frontal gyrus, and the superior and inferior parietal lobules in aerobically trained older adults, together with reduced activity in the dorsal region of anterior cingulate cortex which was related to behavior conflicts (Colcombe et al., 2004). Nevertheless, in our study, none of the effect size in processing speed and executive function showed significant difference from zero. Liu-Ambrose's group also conducted the test of EXIT-25, an assessment of global executive function and did not find any improvement after aerobic training (Liu-Ambrose et al., 2016). Considering the special role of relevant lobes in processing speed and executive function, we proposed that the location of vascular disorder might be one variant involved. However, none of the included studies reported such information and thus it is needed settling in future investigation. Another factor which might get involved in cognitive benefits of these specific aspects induced by aerobic exercise was sex. A meta-analysis demonstrated greater cognitive gains in studies with over $50 \%$ participant population being women, indicating that women could benefit more from aerobic exercise in cognition compared to their male counterparts (Colcombe and Kramer, 2003). Similarly, another meta-analysis has found better executive function performance in studies with higher percentage of women after aerobic training (Barha et al., 2017). Baker's group investigated sex-specific effect of aerobic exercise in old adults with mild cognitive impairment. Men and women showed similar improvement in Trail B Test and Task Switching, the tests designed for set shifting performance. For Stroop Test (test for response inhibition) and Symbol Digit Modalities Test (test for processing speed), however, only women gained benefits while aerobic training had no effect on men (Baker et al., 2010). In our study, all trials included for analysis of processing speed and executive function are male dominant except the one conducted by Liu-Ambrose et al. (2016). And there were more men when considering the total number of participants. The secondary analysis of Tang's study also found female stroke survivors benefited more in set shifting and response inhibition (Khattab et al., 2019). Females had greater progression in white matter hyperintensity while this change in males was not significant according to report from Liu-Ambrose (Dao et al., 2019). Among the underlying factors, the difference in BDNF level might be of important influence. Animal models suggested positive effect of estrogen on BDNF (Blanc et al., 2010). The gene coding BDNF contains a sequence similar to the target of estrogen. The reduction of BDNF mRNA could be rescued by estrogen supplement in ovariectomized animals (Singh et al., 1995; Sohrabji et al., 1995). In the case of global cerebral ischemia, the extranuclear estrogen receptors get involved in ERK-Akt-CREB-BDNF signaling and activation of this pathway is associated with neuroprotection and cognitive preservation (Yang et al., 2010). Women have higher plasma $\mathrm{BDNF}$ level. Lower level of BDNF is related to further reduction of whole brain and frontal white matter volumes only in women (Komulainen et al., 2008; Driscoll et al., 2012). The secondary 
analysis of study of Liu-Ambrose et al. also showed increased level of BDNF level in women but decreased concentration in men (Barha Cindy et al., 2017).

However, these results should be interpreted carefully, as some effect size was evaluated from small number of studies, limiting the precision of pooled effects. Meanwhile, we restricted the study language to English, which might cause bias in this review. In addition, in this analysis, stroke is still the main type of disease studied and more trials should be conducted in other types of ischemic cerebrovascular disease to establish a comprehensive understanding of the cognitive benefits of aerobic exercise in such kind of disorder. Moreover, other factors like type, location and severity of stroke, education status, motor deflects were only available in a few studies, making it difficult for us to investigate whether they might impact on effect size. Only four of the studies included reported attendance and compliance of intervention. And we considered it great value to study on the influence of participants' adherence to training program. Ultimately, it is worthy of effort to explore gains in other cognitive domains (for example, verbal fluency and language) after aerobic training. Future studies are needed to confirm and expand our findings.

\section{CONCLUSION}

The results of our analysis indicated that aerobic exercise might exert positive effects on cognition in ischemic cerebrovascular disorder survivors, especially for those already with cognitive impairment. Moderate intensity training tends to be the applicable selection. Duration of the training program and the initiation time of exercise of stroke survivors were not the

\section{REFERENCES}

Askim, T., Dahl, A. E., Aamot, I. L., Hokstad, A., Helbostad, J., and Indredavik, B. (2014). High-intensity aerobic interval training for patients 3-9 months after stroke. A feasibility study. Physiother. Res. Int. 19, 129-139. doi: 10.1002/pri.1573

Baker, L. D., Frank L. L., Foster-Schubert, K., Green, P. S., Wilkinson, C. W., McTiernan, A., et al. (2010). Effects of aerobic exercise on mild cognitive impairment: a controlled trial. Arch. Neurol. 67, 71-79. doi: 10.1001/archneurol.2009.307

Barha Cindy, K., Hsiung Ging-Yuek, R., Best John, R., Davis Jennifer, C., Eng Janice, J., Jacova, C., et al. (2017). Sex difference in aerobic exercise efficacy to improve cognition in older adults with vascular cognitive impairment: secondary analysis of a randomized controlled trial. J. Alzheimers Dis. 60, 1397-1410. doi: 10.3233/JAD-170221

Barha, C. K., Davis, J. C., Falck, R. S., Nagamatsu, L. S., and Liu-Ambrose, T. (2017). Sex differences in exercise efficacy to improve cognition: a systematic review and meta-analysis of randomized controlled trials in older humans. Front. Neuroendocrinol. 46, 71-85. doi: 10.1016/j.yfrne.2017.04.002

Bettio, L., Thacker, J. S., Hutton, C., and Christie, B. R. (2019). Modulation of synaptic plasticity by exercise. Int. Res. Neurobiol. 147, 295-322. doi: 10.1016/bs.irn.2019.07.002

Billinger, S. A., Arena, R., Bernhardt, J., Eng, J. J., Franklin, B. A., Johnson, C. M., et al. (2014). Physical activity and exercise recommendations for stroke survivors: a statement for healthcare professionals from the American Heart Association/American Stroke Association. Stroke 45, 2532-2553. doi: 10.1161/STR.0000000000000022 predictors for cognitive gains. Our study did not find favorable effects of aerobic exercise on executive function and processing speed. Future work is needed to explore the optimal exercise parameters and benefiting population.

\section{DATA AVAILABILITY STATEMENT}

The datasets presented in this study can be found in online repositories. The names of the repository/repositories and accession number(s) can be found in the article/supplementary material.

\section{AUTHOR CONTRIBUTIONS}

YS contributed to conception and design of the study. YS, QH, and YX conducted the database search, study selection, data collection, and extraction. Data analysis was performed by QH and WZ. YS, QH, and SZ wrote the manuscript. All authors contributed to manuscript revision, read, and approved the submitted version.

\section{FUNDING}

This work was supported by National Natural Science Foundation of China (81772454 and 81971237) and Jiangsu Science and Technology Department (BE2017734).

\section{ACKNOWLEDGMENTS}

All authors are acknowledged for their contributions to this study.

Blanc, F., Poisbeau, P., Sellal, F., Tranchant, C., de Seze, J., and André, G., (2010). Alzheimer disease, memory and estrogen. Rev. Neurol. 166, 377-388. doi: 10.1016/j.neurol.2009.07.010

Bo, W., Lei, M., Tao, S., Jie, L. T., Qian, L., Lin, F. Q., et al. (2019). Effects of combined intervention of physical exercise and cognitive training on cognitive function in stroke survivors with vascular cognitive impairment: a randomized controlled trial. Clin. Rehabil. 33, 54-63. doi: 10.1177/026921551 8791007

Bonsu, B., and Terblanche, E. (2016). The training and detraining effect of high-intensity interval training on post-exercise hypotension in young overweight/obese women. Eur. J. Appl. Physiol. 116, 77-84. doi: 10.1007/s00421-015-3224-7

Cefis, M., Prigent-Tessier, A., Quirié, A., Pernet, N., Marie, C., and Garnier, P. (2019). The effect of exercise on memory and BDNF signaling is dependent on intensity. Brain Struct. Funct. 224, 1975-1985. doi: 10.1007/s00429-019-01889-7

Chen, Z., Hu, Q., Xie, Q., Wu, S., Pang, Q., Liu, M., et al. (2019). Effects of treadmill exercise on motor and cognitive function recovery of MCAO mice through the caveolin-1/VEGF signaling pathway in ischemic penumbra. Neurochem. Res. 44, 930-946. doi: 10.1007/s11064-019-02728-1

Colcombe, S., and Kramer, A. F. (2003). Fitness effects on the cognitive function of older adults: a meta-analytic study. Psychol. Sci. 14, 125-130. doi: 10.1111/1467-9280.t01-1-01430

Colcombe, S. J., Erickson K. I., Raz, N., Webb, A. G., Cohen, N. J., McAuley, E., et al. (2003). Aerobic fitness reduces brain tissue loss in aging humans.. J. Gerontol. 58, M176-M180. doi: 10.1093/gerona/58. 2.M176 
Colcombe, S. J., Kramer A. F., Erickson, K. I., Scalf, P., McAuley, E., Cohen, N. J., et al. (2004). Cardiovascular fitness, cortical plasticity, and aging. PNAS 101, 3316-3321. doi: 10.1073/pnas.0400266101

Cotman, C. W., Berchtold, N. C., and Christie, L. A. (2007). Exercise builds brain health: key roles of growth factor cascades and inflammation. Trends Neurosci. 30, 464-472. doi: 10.1016/j.tins.2007.06.011

Dao, E., Barha, C. K., Best, J. R., Hsiung, G. Y., Tam, R., and LiuAmbrose, T. (2019). The effect of aerobic exercise on white matter hyperintensity progression may vary by sex. Can. J. Aging 38, 236-244. doi: $10.1017 /$ S0714980818000582

Debreceni-Nagy, A., Horvath, J., Bajuszne Kovacs, N., Fulop, P., and Jenei, Z. (2019). The effect of low-intensity aerobic training on cognitive functions of severely deconditioned subacute and chronic stroke patients: a randomized, controlled pilot study. Int. J. Rehabil. Res. 42, 275-279. doi: 10.1097/MRR.0000000000000346

Diamond, A. (2013). Executive functions. Annu. Rev. Psychol. 64, 135-168. doi: 10.1146/annurev-psych-113011-143750

Dichgans, M., and Leys, D. (2017). Vascular cognitive impairment. Circ. Res. 120, 573-591. doi: 10.1161/CIRCRESAHA.116.308426

Ding, Q., Vaynman, S., Akhavan, M., Ying, Z., and Gomez-Pinilla, F. (2006a). Insulin-like growth factor I interfaces with brain-derived neurotrophic factormediated synaptic plasticity to modulate aspects of exercise-induced cognitive function. Neuroscience 140, 823-833. doi: 10.1016/j.neuroscience.2006.02.084

Ding, Y.-H., Li, J., Zhou, Y., Rafols, J. A., Clark, J. C., and Ding, Y. (2006b). Cerebral angiogenesis and expression of angiogenic factors in aging rats after exercise. Curr. Neurovasc. Res. 3, 15-23. doi: 10.2174/156720206775541787

Driscoll, I., Martin, B., An, Y., Maudsley, S., Ferrucci, L., Mattson, M. P.», et al. (2012). Plasma BDNF is associated with age-related white matter atrophy but not with cognitive function in older, non-demented adults. PLOS ONE 7:35217. doi: 10.1371/journal.pone.0035217

Duncombe, J., Kitamura, A., Hase, Y., Ihara, M., Kalaria, R. N., and Horsburgh, K. (2017). Chronic cerebral hypoperfusion: a key mechanism leading to vascular cognitive impairment and dementia. Closing the translational gap between rodent models and human vascular cognitive impairment and dementia. Clin. Sci. 131, 2451-2468. doi: 10.1042/CS20160727

El-Tamawy, M. S., Abd-Allah, F., Ahmed, S. M., Darwish, M. H., and Khalifa, H. A. (2014). Aerobic exercises enhance cognitive functions and brain derived neurotrophic factor in ischemic stroke patients. NeuroRehabilitation 34, 209-213. doi: 10.3233/NRE-131020

Frater, J., Lie, D., Bartlett, P., and McGrath, J. J. (2018). Insulin-like growth factor 1 (IGF-1) as a marker of cognitive decline in normal ageing: a review. Ageing Res. Rev. 42, 14-27. doi: 10.1016/j.arr.2017.12.002

Gates, N., Singh, M. A. F., Sachdev, P. S., and Valenzuela, M. (2013). The effect of exercise training on cognitive function in older adults with mild cognitive impairment: a meta-analysis of randomized controlled trials. Am. J. Geriatr. Psychiatry 21, 1086-1097. doi: 10.1016/j.jagp.2013.02.018

Gong, X., Ma, M., Fan, X., Li, M., Liu, Q., Liu, X., et al. (2012). Down-regulation of IGF-1/IGF-1R in hippocampus of rats with vascular dementia. Neurosci. Lett. 513, 20-24. doi: 10.1016/j.neulet.2012.01.077

Gorelick, P., Scuteri, A., Black, S., Decarli, C., Greenberg, S., Iadecola, C., et al. (2011). Vascular contributions to cognitive impairment and dementia: astatement for healthcare professionals from the American Heart Association/American Stroke Association. Stroke 42, 2672-2713. doi: 10.1161/STR.0b013e3182299496

Han, P., Zhang, W., Kang, L., Ma, Y., Fu, L., Jia, L., et al. (2017). "Clinical evidence of exercise benefits for stroke," in Exercise for Cardiovascular Disease Prevention and Treatment, ed. J. Xiao (Springer: Singapore), 131-151. doi: 10.1007/978-981-10-4304-8_9

Hasegawa, N., Fujie, S., Horii, N., Miyamoto-Mikami, E., Tsuji, K., Uchida, M., et al. (2018). Effects of different exercise modes on arterial stiffness and nitric oxide synthesis. Med. Sci. Sports Exerc. 50, 1177-1185. doi: 10.1249/MSS.0000000000001567

Hsu, C. L., Best, J. R., Davis, J. C., Nagamatsu, L. S., Wang, S., Boyd, L. A., et al. (2018). Aerobic exercise promotes executive functions and impacts functional neural activity among older adults with vascular cognitive impairment. Brit. J. Sport Med. 52, 184-191. doi: 10.1136/bjsports-2016-096846

Hsu, C. L., Best, J. R., Wang, S., Voss, M. W., Hsiung, R. G. Y., Munkacsy, M., et al. (2017). The impact of aerobic exercise on fronto-parietal network connectivity and its relation to mobility: an exploratory analysis of a 6-month randomized controlled trial. Front. Hum. Neurosci. 11:344. doi: 10.3389/fnhum.2017. 00344

Hurd, M. D., Martorell, P., Delavande, A., Mullen, K. J., and Langa, K. M. (2013). Monetary costs of dementia in the United States. New Engl. J. Med. 368, 1326-1334. doi: 10.1056/NEJMsa1204629

Ihle-Hansen, H., Langhammer, B., Lydersen, S., Gunnes, M., Indredavik, B., and Askim, T. (2019). A physical activity intervention to prevent cognitive decline after stroke: Secondary results from the Life After STroke. study, an 18-month randomized controlled trial. J. Rehabil. Med. 51, 646-651. doi: 10.2340/16501977-2588

Jensen, A. R. (2006). Clocking the Mind: Mental Chronometry and Individual Differences. Elsevier ScienceAQ location.

Johns Hopkins Medicine (2020). Stroke Recovery Timeline. Available online at: https://www.hopkinsmedicine.org/health/conditions-and-diseases/stroke/ stroke-recovery-timeline (accesssed June 21, 2020).

Kalaria, R. N., Akinyemi, R., and Ihara, M. (2016). Stroke injury, cognitive impairment and vascular dementia. BBA-Mol. Basis Dis. 1862, 915-925. doi: 10.1016/j.bbadis.2016.01.015

Khattab, S., Eng, J. J., Liu-Ambrose, T., Richardson, J., MacDermid, J., and Tang, A. (2019). Sex differences in the effects of exercise on cognition poststroke: secondary analysis of a randomized controlled trial. J. Rehabil. Med. 51. doi: 10.2340/16501977-2615

Kleemeyer, M. M., Kühn, S., Prindle, J., Bodammer, N. C., Brechtel, L., Garthe, A., et al. (2016). Changes in fitness are associated with changes in hippocampal microstructure and hippocampal volume among older adults. Neuroimage 131, 155-161. doi: 10.1016/j.neuroimage.2015.11.026

Komulainen, P., Pedersen, M., Hänninen, T., Bruunsgaard, H., Lakka, T. A., Kivipelto, M., et al. (2008). BDNF is a novel marker of cognitive function in ageing women: the DR's EXTRA study. Neurobiol. Learn. Mem. 90, 596-603. doi: 10.1016/j.nlm.2008.07.014

Liu-Ambrose, T., Best, J. R., Davis, J. C., Eng, J. J., Lee, P. E., Jacova, C., et al. (2016). Aerobic exercise and vascular cognitive impairment: a randomized controlled trial. Neurology 87, 2082-2090. doi: 10.1212/WNL.0000000000003332

Loprinzi, P. D., Herod, S. M., Cardinal, B. J., and Noakes, T. D. (2013). Physical activity and the brain: a review of this dynamic, bi-directional relationship. Brain Res. 1539, 95-104. doi: 10.1016/j.brainres.2013.10.004

Luca, M., and Luca, A. (2019). Oxidative stress-related endothelial damage in vascular depression and vascular cognitive impairment: beneficial effects of aerobic physical exercise. Oxid. Med. Cell. Longev. 2019:8067045. doi: 10.1155/2019/8067045

Luo, D., Wan, X., Liu, J., and Tong, T. (2018). Optimally estimating the sample mean from the sample size, median, mid-range, and/or mid-quartile range. Stat.Methods Med. Res. 27, 1785-1805. doi: 10.1177/0962280216669183

MacKay-Lyons, M. J., and Makrides, L. (2002). Exercise capacity early after stroke. Arch. Phys. Med. Rehab. 83, 1697-1702. doi: 10.1053/apmr.2002.36395

Manuela Crispim Nascimento, C., Rodrigues Pereira, J., Pires de Andrade, L., Garuffi, M., Leme Talib, L., Vicente Forlenza, O., et al. (2014). Physical exercise in MCI elderly promotes reduction of pro-inflammatory cytokines and improvements on cognition and BDNF peripheral levels. Curr. Alzheimer Res. 11, 799-805. doi: 10.2174/156720501108140910122849

Moraine, J.-J., Lamotte, M., Berré, J., Niset, G., Leduc, A., and Naeijel, R. (1993). Relationship of middle cerebral artery blood flow velocity to intensity during dynamic exercise in normal subjects. Eur. J. Appl. Physiol. 67, 35-38. doi: 10.1007/BF00377701

Morris, T. P., Fried, P. J., Macone, J., Stillman, A., Gomes-Osman, J., CostaMiserachs, D., et al. (2020). Light aerobic exercise modulates executive function and cortical excitability. Eur. J. Neurosci. 51, 1723-1734. doi: 10.1111/ejn.14593

Navarro-Martínez, R., Fernández-Garrido, J., Buigues, C., Torralba-Martínez, E., Martinez-Martinez, M., Verdejo, Y., et al. (2015). Brain-derived neurotrophic factor correlates with functional and cognitive impairment in non-disabled older individuals. Exp. Gerontol. 72, 129-137. doi: 10.1016/j.exger.2015.10.001

Nave, A. H., Rackoll, T., Grittner, U., Blasing, H., Gorsler, A., Nabavi, D. G., et al. (2019). Physical fitness training in patients with subacute stroke (PHYSSTROKE): multicentre, randomised controlled, endpoint blinded trial. BMJ 366:15101. doi: 10.1136/bmj.15101

Northey, J. M., Cherbuin, N., Pumpa, K. L., Smee, D. J., and Rattray, B. (2018). Exercise interventions for cognitive function in adults older than 
50: a systematic review with meta-analysis. Br. J. Sports Med. 52, 154-160. doi: 10.1136/bjsports-2016-096587

Oberlin, L. E., Waiwood, A. M., Cumming, T. B., Marsland, A. L., Bernhardt, J., and Erickson, K. I. (2017). Effects of physical activity on poststroke cognitive function. Stroke 48, 3093-3100. doi: 10.1161/STROKEAHA.117.017319

Palmefors, H., DuttaRoy, S., Rundqvist, B., and Börjesson, M. (2014). The effect of physical activity or exercise on key biomarkers in atherosclerosis-a systematic review. Atherosclerosis 235, 150-161. doi: 10.1016/j.atherosclerosis.2014.04.026

Ploughman, M., Eskes, G. A., Kelly, L. P., Kirkland, M. C., Devasahayam, A. J., Wallack, E. M., et al. (2018). Combining aerobic exercise and cognitive training in chronic stroke; enhanced cognition predicted by IGF-1. Int. J. Stroke 13:32. doi: $10.1177 / 1747493018789543$

Ploughman, M., Eskes, G. A., Kelly, L. P., Kirkland, M. C., Devasahayam, A. J., Wallack, E. M., et al. (2019). Synergistic benefits of combined aerobic and cognitive training on fluid intelligence and the role of IGF-1 in chronic stroke. Neurorehabil. Neural Repair 33, 199-212. doi: 10.1177/1545968319832605

Prakash, R. S., Snook, E. M., Motl, R. W., and Kramer, A. F. (2010). Aerobic fitness is associated with grey matter volume and white matter integrity in multiple sclerosis. Brain Res. 1341, 41-51. doi: 10.1016/j.brainres.2009.06.063

Quaney, B. M., Boyd, L. A., McDowd, J. M., Zahner, L. H., He, J., Mayo, M. S., et al. (2009). Aerobic exercise improves cognition and motor function poststroke. Neurorehab. Neural. Res. 23, 879-885. doi: 10.1177/1545968309338193

Riebe, D. (2018). ACSM's Guidelines for Exercise Resting and Prescription, 10th Edn. Philadelphia: Wolters Kluwer.

Rosenfeldt, A. B., Linder, S. M., Davidson, S., Clark, C., Zimmerman, N. M., Lee, J. J., et al. (2019). Combined aerobic exercise and task practice improve health-related quality of life poststroke: apreliminary analysis. Arch. Phys. Med. Rehabil. 100, 923-930. doi: 10.1016/j.apmr.2018.11.011

Ruscheweyh, R., Willemer, C., Krüger, K., Duning, T., Warnecke, T., Sommer, J., et al. (2011). Physical activity and memory functions: an interventional study. Neurobiol. Aging 32, 1304-1319. doi: 10.1016/j.neurobiolaging.2009.08.001

Sahathevan, R., Brodtmann, A., and Donnan, G. A. (2012). Dementia, stroke, and vascular risk factors; a review. Int. J. Stroke 7, 61-73. doi: 10.1111/j.1747-4949.2011.00731.x

Sanders, L. A.-O., Hortobágyi, T., la Bastide-van Gemert, S. A.-O., van der Zee, E. A., and van Heuvelen, M. J. G. (2019). Dose-response relationship between exercise and cognitive function in older adults with and without cognitive impairment: a systematic review and meta-analysis. PLOS ONE 14:0210036. doi: 10.1371 /journal.pone.0210036

Sandroff, B. M., and Motl, R. W. (2012). Fitness and cognitive processing speed in persons with multiple sclerosis: a cross-sectional investigation. J. Clin. Exp. Neuropsyc. 34, 1041-1052. doi: 10.1080/13803395.2012.715144

Schmidt, W., Endres, M., Dimeo, F., and Jungehulsing, G. J. (2013). Train the vessel, gain the brain: physical activity and vessel function and the impact on stroke prevention and outcome in cerebrovascular disease. Cerebrovasc. Dis. 35, 303-312. doi: 10.1159/000347061

Singh, M., Meyer, E. M., and Simpkins, J. W. (1995). The effect of ovariectomy and estradiol replacement on brain-derived neurotrophic factor messenger ribonucleic acid expression in cortical and hippocampal brain regions of female Sprague-Dawley rats. Endocrinology 136, 2320-2324. doi: 10.1210/endo.136.5.7720680

Sohrabji, F., Miranda, R. C., and Toran-Allerand, C. D. (1995). Identification of a putative estrogen response element in the gene encoding brainderived neurotrophic factor. PNAS 92:11110. doi: 10.1073/pnas.92. 24.11110

Song, D., Yu, D. S. F., Li, P. W. C., and Lei, Y. (2018). The effectiveness of physical exercise on cognitive and psychological outcomes in individuals with mild cognitive impairment: a systematic review and meta-analysis. Int. J. Nurs. Stud. 79, 155-164. doi: 10.1016/j.ijnurstu.2018.01.002

Stephens, S., Kenny, R., Rowan, E., Allan, L., Kalaria, R., Bradbury, M., et al. (2004). Neuropsychological characteristics of mild vascular cognitive impairment and dementia after stroke. Int. J. Geriatr. Psych. 19, 1053-1057. doi: $10.1002 /$ gps.1209
Stern, Y., MacKay-Brandt, A., Lee, S., McKinley, P., McIntyre, K., Razlighi, Q., et al. (2017). Effect of aerobic exercise on cognition in younger adults: a randomized clinical trial. Stroke 48, 3093-3100. doi: 10.1212/WNL.0000000000007003

Tang, A., Eng, J. J., Krassioukov, A. V., Madden, K. M., Mohammadi, A., Tsang, M. Y., et al. (2014). Exercise-induced changes in cardiovascular function after stroke: a randomized controlled trial. Int. J. Stroke 9, 883-889. doi: $10.1111 /$ ijs. 12156

Tang, A., Eng, J. J., Krassioukov, A. V., Tsang, T. S., and Liu-Ambrose, T. (2016). High- and low-intensity exercise do not improve cognitive function after stroke: a randomized controlled trial. J. Rehabil. Med. 48, 841-846. doi: 10.2340/16501977-2163

Tiozzo, E., Youbi, M., Dave, K., Perez-Pinzon, M., Rundek, T., Sacco, R. L., et al. (2015). Aerobic, resistance, and cognitive exercise training poststroke. Stroke 46, 2012-2016. doi: 10.1161/STROKEAHA.114.006649

Van der Flier, W. M., Skoog, I., Schneider, J. A., Pantoni, L., Mok, V., Chen, C. L. H., et al. (2018). Vascular cognitive impairment. Nat. Rev. Dis. Primers 4:18003. doi: $10.1038 /$ nrdp. 2018.3

Van Praag, H., Kempermann, G., and Gage, F. H. (1999). Running increases cell proliferation and neurogenesis in the adult mouse dentate gyrus. Nat. Neurosci. 2, 266-270. doi: 10.1038/6368

Vaynman, S., Ying, Z., and Gomez-Pinilla, F. (2004). Hippocampal BDNF mediates the efficacy of exercise on synaptic plasticity and cognition. Eur. J. Neurosci. 20, 2580-2590. doi: 10.1111/j.1460-9568.2004.03720.x

Wallin, A., Roman, G. C., Esiri, M., Kettunen, P., Svensson, J., Paraskevas, G. P., et al. (2018). Update on vascular cognitive impairment associated with subcortical small-vessel disease. J. Alzheimers Dis. 62, 1417-1441. doi: 10.3233/JAD-170803

Wan, X., Wang, W., Liu, J., and Tong, T. (2014). Estimating the sample mean and standard deviation from the sample size, median, range and/or interquartile range. BMC Med. Res. Methodol. 14:135. doi: 10.1186/1471-2288-14-135

Yang, L. C., Zhang Q.-C., Zhou C.-F, Yang, F., Zhang, Y.-d., Wang, R.-m., et al. (2010). Extranuclear estrogen receptors mediate the neuroprotective effects of estrogen in the rat hippocampus. PLoS ONE 5:9851. doi: 10.1371/journal.pone.0009851

Young, J., Angevaren, M., Rusted, J., and Tabet, N. (2015). Aerobic exercise to improve cognitive function in older people without known cognitive impairment. Cochrane Database Syst. Rev. 2015:CD005381. doi: 10.1002/14651858.CD005381.pub4

Zettel-Watson, L., Suen, M., Wehbe, L., Rutledge, D. N., and Cherry, B. J. (2015). Aging well: processing speed inhibition and working memory related Sto balance and aerobic endurance. Geriatr. Gerontol. Int. 17, 108-115. doi: 10.1111/ggi. 12682

Zheng, G., Zhou, W., Xia, R., Tao, J., and Chen, L. (2016). Aerobic exercises for cognition rehabilitation following stroke: a systematic review. J. Stroke Cerebrovasc. Dis. 25, 2780-2789. doi: 10.1016/j.jstrokecerebrovasdis.2016.07.035

Zhu, Y., Wu, H., Qi, M., Wang, S., Zhang, Q., Zhou, L., et al. (2018). Effects of a specially designed aerobic dance routine on mild cognitive impairment. Clin. Interv. Aging 13, 1691-1700. doi: 10.2147/CIA.S1 63067

Conflict of Interest: The authors declare that the research was conducted in the absence of any commercial or financial relationships that could be construed as a potential conflict of interest.

Copyright (C) $2020 \mathrm{Shu}, \mathrm{He}, \mathrm{Xie}$, Zhang, Zhai and Wu. This is an open-access article distributed under the terms of the Creative Commons Attribution License (CC BY). The use, distribution or reproduction in other forums is permitted, provided the original author(s) and the copyright owner(s) are credited and that the original publication in this journal is cited, in accordance with accepted academic practice. No use, distribution or reproduction is permitted which does not comply with these terms. 